\section{RSP}

http://www.rsp.fsp.usp.br/
Revista de Saúde Pública

\title{
Barriers between community screening for visual problems and treatments in a tertiary center
}

Gabriel de Almeida Ferreira', Marcelo Abrão Rezende', Roberta Lilian Fernandes de Sousa Meneghim', Silvana Artioli Schellini'

' Universidade Estadual Paulista. Faculdade de Medicina de Botucatu. Departamento de Oftalmologia, Otorrinolaringologia e Cirurgia de Cabeça e Pescoço. São Paulo, SP, Brasil

\section{ABSTRACT}

OBJECTIVE: To evaluate the effectiveness of mobile ophthalmic unit screenings and to investigate barriers between community care and resolution of the problem at a tertiary center.

METHODS: This prospective study evaluated a convenience sample from 10 municipalities in São Paulo State, Brazil. Patients were assessed in the municipality by a mobile ophthalmic unit and underwent a complete ophthalmic consultation. Patients were referred as warranted to a tertiary hospital.

RESULTS: The mobile ophthalmic unit screened 1,928 individuals and 714 (37\%) were referred. The mean age of the referred patients was $57.12(\mathrm{SD}=19.5)$ years with best corrected visual acuity of 0.37 (SD = 0.36) $\log$ MAR. Forty-seven (6.6\%) patients were blind and $185(26.5 \%)$ were visually impaired. Cataracts (44.7\%) and pterygium (14.7\%) accounted for most referrals. Of those referred, $67.1 \%$ presented to the tertiary center. The diagnosis by the mobile ophthalmic unit corresponded to the one by the tertiary center in $88.5 \%$ of the cases. There were a significantly higher number of blind and visually impaired persons among those who presented to the hospital. There was a significantly greater attendance among patients living in more distant municipalities from the reference center with a higher number of inhabitants and a greater number of ophthalmologists in the cities of origin ( $\mathrm{p}<0.05$, all comparisons). Complete treatment was performed in $65.6 \%$ of patients, and loss to follow-up was the main cause of incomplete treatment in $50.7 \%$ of patients. A total of 313 cataract surgeries were performed, which reduced the number of blind patients from 20 to 2 and of visually impaired individuals from 87 to 2 ( $p<0.001)$.

CONCLUSIONS: Only $37 \%$ of the patients assessed by a mobile ophthalmic unit required referral to a tertiary hospital. Among the referred patients, $67.1 \%$ presented to the hospital, and complete resolution after treatment was approximately $65.5 \%$. There was a significant improvement in visual acuity and a reduction in the prevalence of blindness and visual impairment postoperatively.

DESCRIPTORS: Blindness, rehabilitation. Eye Health Services. Triage. Health Services Accessibility. Tertiary Healthcare. Outcome and Process Assessment (Health Care).

Copyright: This is an open-access article distributed under the terms of the Creative Commons Attribution License, which permits unrestricted use, distribution, and reproduction in any medium, provided that the original author and source are credited. 


\section{INTRODUCTION}

Vision-related conditions are increasing worldwide because of demographic transition and aging populations ${ }^{1}$. In 2010, the World Health Organization (WHO) estimated that 32.4 million persons were blind globally ( $0.5 \%$ of the world population) and 191 million were visually impaired ( $2.8 \%$ of the world population) $)^{2}$.

A lack of optical correction is responsible for $43 \%$ of the visual impairment followed by cataract $(33 \%)^{3}$. Both of them are considered reversible causes of visual impairment. However, barriers to access health services may also be a factor in addressing these causes. These barriers can be related to the patient (unperceived low vision, lack of a companion, and fear of consultation or surgery) or services (lack of financial conditions or lack of accessibility) ${ }^{4}$.

The Brazilian Unified Health System (SUS) is a public and universal health system. However, ophthalmologic coverage in Brazil is suboptimal because of the large land mass of the country and socioeconomic and developmental differences. Mobile ophthalmic units (MOU) represent a means of overcoming some barriers, which can facilitate the population access to ophthalmic care in underserved regions. Most eye diseases can be treated with a properly equipped $\mathrm{MOU}$, and the remaining conditions that require specialized or surgical treatment can be referred to specialized hospitals.

The MOU are a relative recent project in Brazil. This study evaluates the effectiveness of the care using MOU screening in the community. Additionally, this study investigated the barriers between community care and the resolution of the ophthalmic problem at the reference center at a tertiary hospital.

\section{METHODS}

This prospective study was approved by the Research Ethics Committee of the Faculdade de Medicina of the Universidade Estadual Paulista, São Paulo, Brazil, and it adhered to the tenets of the Declaration of Helsinki. All patients who participated were required to sign an informed consent form.

The study had a convenience sample comprised of subjects with ocular complaints from 10 municipalities of the central-western region of the state of São Paulo, Brazil, in 2015 (Table 1). All patients were screened by the MOU in the community, and they received optical prescription or clinical treatment whenever needed. Patients who needed specialized clinical or surgical treatment were referred to the Clinic Hospital of the Faculdade de Medicina de Botucatu (CH-FMB), which is considered the reference center for the region where this study was conducted.

All care was free of cost, provided by the SUS. The MOU was comprised of two ophthalmologists, two ophthalmic technicians, and three ophthalmology residents. The MOU evaluated an average of 150 patients per visit in each municipality. The transportation to the CH-FMB was provided by the municipalities of origin without costs.

Data were collected on demographics of the municipality of origin [per capita GDP (gross domestic product), average per capita family income, and number of inhabitants, provided by the Brazilian Institute of Geography and Statistics ${ }^{5,6}$, human development index (HDI) based on the United Nations Development Programme definition ${ }^{7}$, and number of ophthalmologists according to the SUS Department of Informatics ${ }^{8}$. Data were also collected on the ophthalmic care performed at the reference center including the time between MOU screening and patient presentation to the reference center, the number of consultations performed, treatment proposed and performed, number of surgeries, complications, and outcomes. Outcomes were estimated by corrected visual acuity (VA) or resolution of the chief complaint.

Patients were included if they were evaluated in 2015 by the MOU in municipalities of the central-western region of São Paulo State and if they were suspected of having ophthalmic 
Table 1. Demographic data of municipalities visited by the mobile ophthalmology unit in 2015 .

\begin{tabular}{|c|c|c|c|c|c|c|c|}
\hline Municipalities & Screening date & Population & $\begin{array}{l}\text { per capita } \\
\text { Income (R\$) }\end{array}$ & $\begin{array}{l}\text { per capita } \\
\text { GDP }(R \$)\end{array}$ & HDI & $\begin{array}{c}\text { Distance to } \\
\text { hospital }(\mathbf{k m})\end{array}$ & $\begin{array}{c}\text { Number of } \\
\text { ophthalmologists }\end{array}$ \\
\hline Mineiros do Tietê & 2/2/2015 and $24 / 8 / 2015$ & 12,038 & 694.22 & 10795.16 & 0.730 & 67.1 & 0 \\
\hline Piramboia & $9 / 2 / 2015$ & 5,653 & 549.16 & 17558.27 & 0.721 & 44.2 & 0 \\
\hline Taquarituba & $25 / 5 / 2015$ & 22,291 & 613.84 & 19516.97 & 0.701 & 139 & 1 \\
\hline Igaraçu do Tietê & $1 / 6 / 2015$ & 23,362 & 587.44 & 10229.66 & 0.727 & 50.6 & 0 \\
\hline Dois Córregos & $15 / 6 / 2015$ & 24,761 & 720.28 & 20050.38 & 0.725 & 76.8 & 2 \\
\hline Boracéia & $29 / 6 / 2015$ & 4,268 & 708.05 & 30521.77 & 0.754 & 102 & 0 \\
\hline Bariri & $20 / 7 / 2015$ & 31,593 & 771.49 & 24914.02 & 0.750 & 110 & 2 \\
\hline Macatuba & $27 / 7 / 2015$ & 16,259 & 918.61 & 26688.61 & 0.770 & 65.3 & 0 \\
\hline Brotas & 3/8/2015 & 21,580 & 711.01 & 22964.88 & 0.740 & 98.4 & 0 \\
\hline Barra Bonita & $9 / 11 / 2015$ & 35,246 & 903.18 & 16523.66 & 0.788 & 53.8 & 4 \\
\hline
\end{tabular}

GDP: gross domestic product; HDI: human development index.

diseases and needed referral to the tertiary center. Exclusion criteria were refusal to participate in the study and lack of information in the electronic medical records.

The MOU was equipped with two manual refractors (RT 6000; NIDEK Co. Ltd., Gamagori, Japan), two optotype projectors (ES-03 Xenônio, São Paulo, Brazil), two slit lamps (Shinn Nippon Corp., Tokyo, Japan), two Goldmann applanation tonometers (Haag-Streit Holding, Köniz, Switzerland), one non-contact tonometer (CT-60; Topcon Corp., Tokyo, Japan), one autorefractor (Accuref - K Shinn Nippon Corp., Tokyo , Japan), two 78 D lenses (Volk Optical Inc., Mentor, Ohio, USA), two retinoscopes (Welch Allyn Inc., Skaneateles Falls, NY, USA), and three Snellen eye charts. The patients underwent an ophthalmic examination consisting of VA measurement with and without optical correction using the Snellen chart at a distance of five meters. If the patient could not see the largest symbol in the Snellen chart, VA was checked with finger counting, hand movement, and light perception. The VA was converted to logMAR for statistical analysis with the values of 2.10, 2.40, 2.70, and $3.00 \log M A R$ corresponding to finger count, hand movement, light perception, and no light perception, respectively ${ }^{9}$. A torch light was used for external examination. Absence or presence of strabismus was checked with the Hirschberg test and the simple cover and alternating cover tests. Slit lamp examination was performed on the anterior segment and posterior segment; biomicroscopy was performed with a $78 \mathrm{D}$ fundus lens (under medication-induced mydriasis, when necessary). Intraocular pressure was measured with air-puff tonometry followed by Goldmann applanation tonometer if the air-puff tonometer detected intraocular pressure exceeding $20 \mathrm{mmHg}^{10}$.

Examination at the reference center was the same as at the MOU. However, additional diagnostic tests were performed including biometry (IOLMaster 500; Carl Zeiss Meditec, Jena, Germany). All cataract surgery cases were targeted for emmetropia. If dense cataracts precluded optical biometry, axiallength was measured with an ultrasonic contact biometer (SP-1000AP; Sonoptek, China) and the intraocular lens (IOL) power was calculated on the IOLMaster 500.

Blindness and visual impairment were defined according to WHO criteria, with blindness classified as $\mathrm{VA}<20 / 400$ and visual impairment as 20/400 $<\mathrm{VA}<20 / 60$ in the best eye and with the best optical correction ${ }^{11}$.

We defined a fully completed treatment when patients underwent the entire proposed treatment, both surgical and clinical. In the surgical cases, bilateral treatment was considered as indicated. If patients were awaiting evaluation or a surgery at the reference center, the treatment was classified as partial.

All data were tabulated in a spreadsheet and transferred to SPSS 22.0 software (IBM Corp., Armonk, NY, USA) for analysis. The results were evaluated according to frequency of occurrence, mean, and standard deviation. The normal distribution was analyzed by the Kolmogorov-Smirnov and Shapiro-Wilk tests and the subsequent analysis was performed with the relevant tests. The continuous variables are expressed by mean and standard deviation. Statistical significance was classified as $\mathrm{p}<0.05$. 


\section{RESULTS}

This study enrolled 1,951 individuals, of whom 23 were excluded because of a lack of information in the medical records. Thus, 1,928 individuals were evaluated, of whom 714 (37\%) required referral to the tertiary center, which ranged from $13.4 \%$ to $73 \%$ according to the municipality of origin (Figure 1). The mean age of the referred patients was 57.1 (SD = 19.5) years (median $=62$ years, ranging from one to 90 years) and 428 (59.9\%) were females.

The VA was determined in 699 (97.9\%) patients. Mean uncorrected VA (UCVA) in the best eye was 0.54 (SD =0.56) logMAR (approximately 20/60) and mean best corrected VA (BCVA) in the best eye was 0.37 (SD = 0.36) logMAR (approximately 20/50). Forty-seven (6.6\%) patients were blind and $185(26.5 \%)$ were visually impaired. There was a statistically significant association between VA and age, in which VA was worse in older individuals $(r=0.38, p<0.001)$. Blind and visually impaired persons were older, $66.2(\mathrm{SD}=18.9)$ and $66.5(\mathrm{SD}=14.4)$ years respectively, compared to patients with normal VA [53.5 $(\mathrm{SD}=18.6)$ years, $\mathrm{p}<0.001]$.

Three hundred and nineteen (44.7\%) patients were referred for cataract, followed by 107 (15\%) patients for pterygium and 49 (6.9\%) patients for suspicion of glaucoma (Table 2).

Of the 714 referred patients, 479 (67.1\%) presented to the tertiary (reference) center and eight (1.1\%) were still waiting consultation at the time of data collection and were not included in the analysis.

Among the patients who presented, the main reason for referral to the reference center was surgical treatment (349 patients; $72.9 \%)$, followed by clinical follow-up ( $\mathrm{n}=83 ; 17.3 \%$ ), laser treatment for posterior capsule opacification or retina $(n=46$; $9.6 \%)$, or botulinum toxin treatment $(\mathrm{n}=1 ; 0.2 \%)$.

The diagnosis from the MOU and tertiary center was the same in $88.5 \%$ ( 424 of 479 ) of the cases. Most differing diagnoses corresponded to the indication of cataract surgery, in which, after detailed examination and complementary tests, another ocular comorbidity was detected, which contraindicated the surgical treatment (21 cases; $38.2 \%$ of the differing diagnoses).

For the ophthalmic specialties, the lowest agreement between the diagnoses from the MOU and reference center were glaucoma (78.3\%) and retina (81.1\%) (Figure 2).

Age, sex, and BCVA in the best eye were not determinants for presentation to the tertiary service $(p>0.005)$. There was a statistically significantly higher frequency of blindness $(7.5 \%$ versus $5.4 \%$ ) or visual impairment (29.2\% versus $21.6 \%$ ) among patients who presented to the reference center versus those who failed to present $(\mathrm{p}=0.035)$.

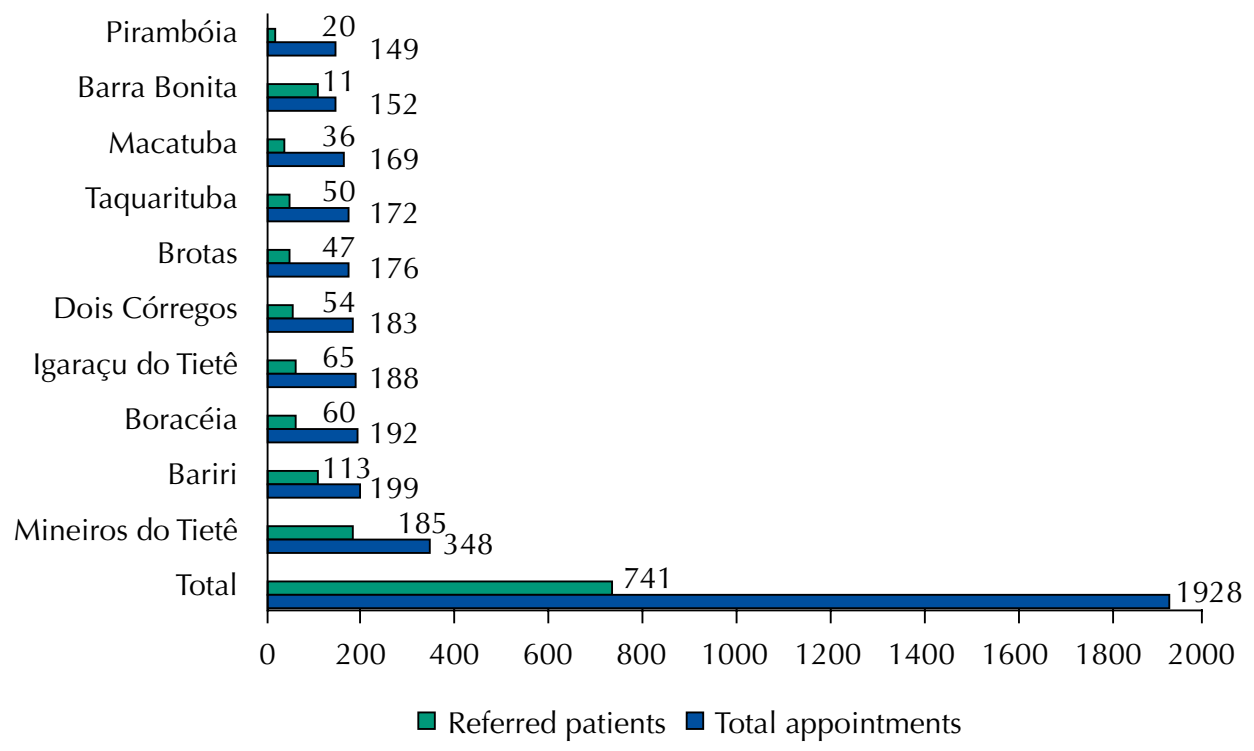

Figure 1. Patients referred by a mobile ophthalmic unit for treatment at a tertiary center in 2015. 
Table 2. Ophthalmic disorders and referral of patients by a mobile ophthalmic unit to a tertiary center in 2015.

\begin{tabular}{lcc}
\hline Disorders & $\mathbf{n}$ & $\%$ \\
\hline Crystalline disorders & 349 & 48.9 \\
Eyelid disorders & 196 & 27.4 \\
Glaucoma & 61 & 8.5 \\
Retinal disorders & 41 & 5.7 \\
Corneal and ocular surface disorders & 27 & 3.8 \\
Strabismus & 20 & 2.8 \\
Refractive changes & 8 & 1.1 \\
Orbital disorders & 7 & 1.0 \\
Uveal disorders & 5 & 0.7 \\
\hline
\end{tabular}

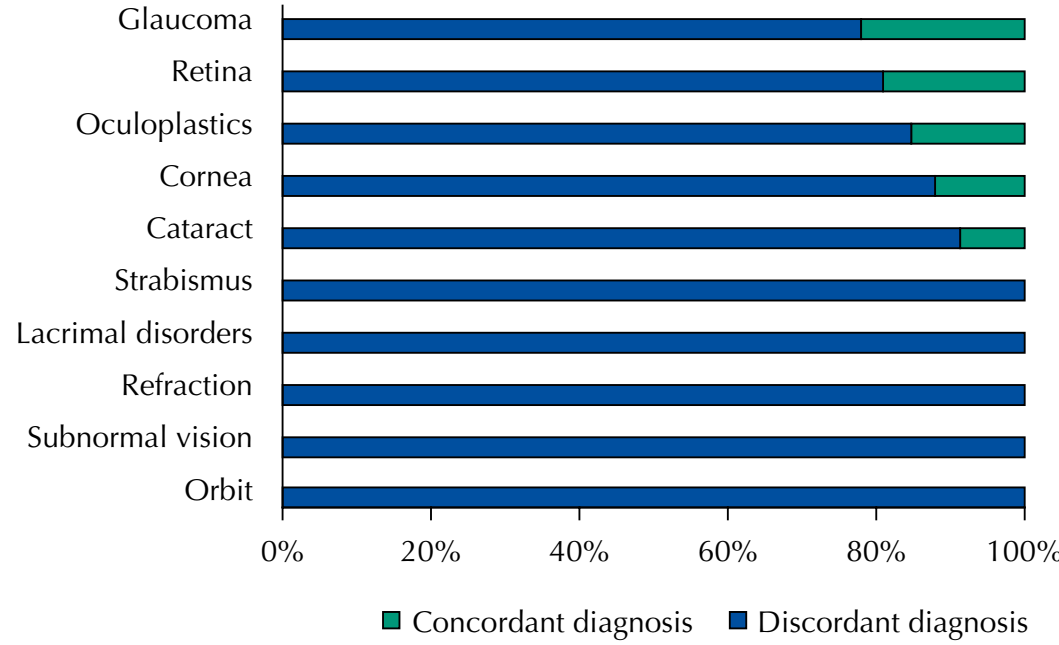

Figure 2. Distribution of the agreement in diagnoses between a mobile ophthalmic unit and a tertiary center according to subspecialty in 2015.

According to the demographics of the municipalities of origin, there was a statistically significantly greater attendance among patients living in more distant municipalities from the reference center $(81.9 \mathrm{~km}$ versus $77.3 \mathrm{~km}, \mathrm{p}=0.034)$, with a higher number of inhabitants $(22,449.2$ versus $19,477.3$ inhabitants, $\mathrm{p}<0.001)$, and with a greater number of ophthalmologists in the cities of origin ( 1.30 versus 0.87 ophthalmologists, $p<0.001)$. The HDI, per capita GDP, and average per capita family income did not influence who presented to the reference center.

The mean time interval between presentation to the $\mathrm{MOU}$ and consultation at the reference center was $133.2(\mathrm{SD}=113.1)$ days. The mean time between the consultation and the necessary surgical procedure was $55.5(\mathrm{SD}=55.4)$ days.

After examination at the reference center, $3.8 \%$ of the patients did not require any further clinical follow-up or surgery. Among those who were referred, $65.6 \%$ underwent complete treatment, $20 \%$ had partial treatment, and $10.4 \%$ received no treatment.

The main causes of partial or non-treatment were loss to follow-up (50.7\%), waiting for the procedure (36.3\%), the patient refused the procedure (9.6\%), and only clinical follow-up was indicated (3.4\%).

A total of 204 (58.8\%) individuals underwent cataract surgery (313 total cataract surgeries), with an average of $5.3(\mathrm{SD}=3.1)$ visits per patient. The mean time between referral by the $\mathrm{MOU}$ and care in the cataract clinic was $81.2(\mathrm{SD}=51.2)$ days. The mean time between the consultation and the cataract procedure was $57.8(\mathrm{SD}=60.9)$ days with an average follow-up of $166.8(\mathrm{SD}=103)$ days.

Complications occurred in 46 (14.7\%) cataract surgeries. Posterior capsule rupture was the most common complication accounting for $39.1 \%$ of them (5.7\% of the surgeries) (Table 3 ). 
Table 3. Complications of cataract surgeries performed at a tertiary reference center in patients referred by a mobile ophthalmic unit in 2015.

\begin{tabular}{lcc}
\hline Complications & n (\% of complications) & \% of total surgeries \\
\hline Posterior capsular rupture & $14(30.4)$ & 4.5 \\
Postoperative positive Seidel & $6(13)$ & 1.9 \\
Corneal decompensation or bullous keratopathy & $5(10.9)$ & 1.6 \\
Zonular disinsertion & $5(10.9)$ & 1.6 \\
Corneal stitch & $4(8.7)$ & 1.3 \\
Posterior dislocation of nucleus & $4(8.7)$ & 1.3 \\
Descemet detachment & $2(4.3)$ & 0.6 \\
Capture of intraocular lens & $1(2.2)$ & 0.3 \\
Iridoplasty & $1(2.2)$ & 0.3 \\
Expulsive hemorrhage & $1(2.2)$ & 0.3 \\
Postoperative cortical rest & $1(2.2)$ & 0.3 \\
Cystoid macular edema & $1(2.2)$ & 0.3 \\
Iris herniation & $1(2.2)$ & 0.3 \\
\hline
\end{tabular}

Data on final VA was available in $149(73 \%)$ cataract patients who underwent surgery. The BCVA improved statistically significantly from $0.63(\mathrm{SD}=0.57) \log \mathrm{MAR}$ at presentation to $0.11(\mathrm{SD}=0.29) \log \mathrm{MAR}$ at the last visit $(\mathrm{p}<0.001)$. Initially, $20(10 \%)$ patients were considered blind and 87 (43.5\%) were visually impaired. After surgery, there was a statistically significant improvement and only two blind (1\%) and two (1\%) visually impaired patients remained $(\mathrm{p}<0.001)$.

\section{DISCUSSION}

The outcomes of this study indicate that, on average, $37 \%$ of the patients among all evaluated municipalities were referred to the specialized ophthalmic service after MOU screening. However, the referral rate greatly varied among municipalities. This variation was likely due to the different profile of the municipalities and different levels of demand.

The evaluation of referrals to specialized ophthalmology services after ophthalmic screening is a subject rarely reported in the literature. A single Brazilian study reported that $8.9 \%$ of 1,010 patients were referred to a primary unit in six months ${ }^{12}$. However, in this study, there was no pent-up demand for services. A Canadian study has reported that, in three years, $9 \%$ of routine eye visits required referral to a specialized $u_{n i t}{ }^{13}$. These percentages are much lower than the ones in our study, which evaluated municipalities with poor access to ophthalmic services and those with a previous pent-up demand for services.

In this study, mean BCVA in the best eye was $0.37(\mathrm{SD}=0.36) \log \mathrm{MAR}$ (approximately 20/50). A British study has reported that the preoperative VA of cataract patients was 0.63 $\log \mathrm{MAR}^{9}$. However, that study addressed only patients with cataract, which evidently reduces mean VA. Additionally, in our study, VA was worse in older patients, in addition to a higher burden of blindness and visual impairment, which can be explained by the higher prevalence of cataract, age-related macular degeneration, and other diseases that decrease VA in this age group.

Our study evaluated a convenience sample comprised of individuals of all ages with ocular complaints. At the MOU screening, 47 (6.6\%) individuals were blind and 185 (26.5\%) were visually impaired. Studies enrolling randomized samples have reported a $2.14 \%$ prevalence of visual impairment in patients over 40 years of age and a $0.68 \%$ prevalence of blindness in the United States of America ${ }^{1}$. However, others have reported greater prevalence of blindness in sub-Saharan Africa (5.7\%), North Africa (4.6\%), Middle East (4.6\%), and South Asia (4.4\%), which are likely due to inequality in health care in different regions of the world ${ }^{2}$. 
A study conducted in São Paulo, SP, Brazil, has reported a prevalence of blindness of 1.1\% and a prevalence of visual impairment of $2 \%^{14}$. A Pan-American study using WHO criteria has evaluated patients over 50 years of age in some countries and it has reported that the average prevalence of blindness ranged from $0.7 \%$ in Argentina to $3 \%$ in Panama, and visual impairment ranged from $8 \%$ to $14.3 \%$ in Uruguay and El Salvador, respectively ${ }^{15}$.

Cataract remains a major cause of global blindness ${ }^{11,16,17}$. In our study, the most common indication for referral to the tertiary hospital was cataract ( $44.7 \%$ of referrals). The prevalence of cataracts in Europe increases with age, which ranges from $5 \%$ for individuals aged 52 to 62 years, $30 \%$ for individuals aged 60 to 69 years, to $64 \%$ for individuals over 70 of age ${ }^{18}$. In a Chinese population with a mean age of $52(\mathrm{SD}=11.8)$ years, the prevalence of cataract was $20.8 \%^{19}$.

In our study, the second most common condition warranting referral was pterygium (15\% of the referrals). Pterygium often requires surgical treatment and advanced cases may cause decreased VA.

A study similar to ours by US Army physicians also with a convenience sample of individuals has shown that most cases (45.3\%) warranting referral were due to anterior segment disorders, followed by oculoplastic problems $(23.9 \%)^{20}$. Hence, despite the different profile of the patients, the distribution of the pathology was similar to our study.

In our study, $67.1 \%$ of the patients referred by the MOU were presented to the reference center. Most of these patients were referred for a surgical procedure (72.9\%). This percentage of presentation to the tertiary center was considered low, as several actions were taken to facilitate it, such as the care was performed in the municipality of origin, the referral was directed to the specialty hospital, and transportation was provided by the health municipalities. The rate of patient presentation to the referral hospital or center after screening has not been reported in the literature. Distance to the referral center, fear of surgery, transportation and expenses, lack of companionship, and the expense of surgery have been reported as barriers to cataract surgery ${ }^{21,22}$. However, some of these reasons are not valid for our study population as the SUS covers the cost of surgery and transportation is guaranteed by the municipalities.

In this study, the factors that influenced non-attendance to the referral center were the absence of blindness or visual impairment, shorter distance to the tertiary service, lower number of inhabitants, and fewer ophthalmologists in the municipalities of origin. The greater attendance rate of blind and visually impaired patients seems obvious because of the personal burden of the reduced vision. The lower attendance of patients from the nearest municipalities may be because they can easily access the service outside of the screening campaigns and small municipalities theoretically have a smaller structure, which would hinder the presence of free transportation.

The diagnoses from the MOU and the reference center were the same in $88.5 \%$ of the cases, which reinforces the reliability of the ophthalmic examination performed by the MOU and the possibility of diagnosing several diseases using basic ophthalmic equipment and a rapid examination.

Of the diverging diagnoses between the MOU and the reference center, most (21/55 or 38.2\%) were due to cataract cases in which surgery was contraindicated because of the identification of concomitant diseases after complementary examinations in the reference center.

The lowest agreement in diagnosis between the MOU and the reference center was for glaucoma (78.3\%) and retinal disease (81.1\%). In the former case, glaucoma suspects were also referred, hence complementary tests are needed to include/exclude glaucoma suspects. Additionally, glaucoma is a diagnosis that depends on physician experience ${ }^{23-26}$. A study ${ }^{27}$ of telemedicine-based referrals has reported greater disagreement in glaucoma and retinal diagnoses, which is similar to our study. 
Treatment at the CH-FMB (the reference center) was considered as completed in $65.6 \%$ of the cases, which seems unsatisfactory. A total of $34.4 \%$ had only partial treatment; however, $50.7 \%$ of them were lost to follow-up. Therefore, if there was no loss to follow-up, the treatment rate could have approached $80 \%$, which is considered adequate.

This outcome indicates that patients seem to have difficulty going for their initial consultation and maintaining regular follow-up. The same factors that influence the initial consultation visit may also influence adherence to other consultations. Some of these factors are distance to the reference center, lack of a companion to take the individual to the consultation, and lack of transportation.

A total of 313 cataract surgeries were performed at the reference center and complications occurred in $14.7 \%$ of the cases. The main complication was posterior capsule rupture, which occurred in $5.7 \%$ of the surgeries. Previous studies have reported posterior capsule rupture rates from $1.8 \%$ to $3.06 \% \%^{28,29}$. A much higher rate has been reported in another study of ophthalmologists in training $(29 \%)^{30}$. The rate of posterior capsule rupture in our study can be considered satisfactory because $\mathrm{CH}-\mathrm{FMB}$ is a teaching hospital with procedures being performed by fellows in training and because it is a reference center with a higher frequency of complicated cases.

In this study, there was a statistically significant reduction of visual impairment and blindness after cataract surgery. For example, there was a reduction of visual impairment from $43.5 \%$ at the initial screening to $1 \%$ postoperatively. Similarly, there was a reduction of blindness from $10 \%$ at the initial screening to $1 \%$ postoperatively.

Our findings also indicate that the MOU can reliably detect the most frequent ophthalmic conditions using simple examination techniques and low financial resources, which reinforces the concept that MOUs are very useful for ophthalmic screening within the SUS.

An important limiting factor of our study was the lack of integration between local ophthalmologists and the team that visited the municipality, which can also represent a barrier to non-attendance and loss to follow-up. Local doctors have direct interaction with patients and their participation would facilitate the referral back to the municipality and improve the chances of follow-up.

In conclusion, the attendance rate of patients referred directly from a MOU to a tertiary center was $67.1 \%$. The main causes for referral were cataract and pterygium. The agreement between the diagnoses by the MOU and the tertiary service was $88.5 \%$. In addition, $65.5 \%$ of the cases underwent complete treatment. After cataract surgery, the burden of visual impairment and blindness decreased appreciably.

\section{REFERENCES}

1. Varma R, Vajaranant TS, Burkemper B, Wu S, Torres M, Hsu C, et al. Visual impairment and blindness in adults in the United States: demographic and geographic variations from 2015 to 2050. JAMA Ophthalmol. 2016;134(7):802-9. https://doi.org/10.1001/jamaophthalmol.2016.1284

2. Stevens GA, White RA, Flaxman SR, Price H, Jonas JB, Keeffe J, et al. Global prevalence of vision impairment and blindness: magnitude and temporal trends, 1990-2010. Ophthalmology. 2013;120(12):2377-84. https://doi.org/10.1016/j.ophtha.2013.05.025

3. Pascolini D, Mariotti SP. Global estimates of visual impairment: 2010. Br J Ophthalmol. 2012;96(5):614-8. https://doi.org/10.1136/bjophthalmol-2011-300539

4. Marmamula S, Khanna RC, Shekhar K, Rao GN. A population-based cross-sectional study of barriers to uptake of eye care services in South India: the Rapid Assessment of Visual Impairment (RAVI) project. BMJ Open. 2014;4(6):e005125. https://doi.org/10.1136/bmjopen-2014-005125

5. Instituto Brasileiro de Geografia e Estatística. Produto Interno Bruto a preços correntes e Produto Interno Bruto per capita segundo as Grandes Regiões, as Unidades da Federação e os Municípios - 2010-2013. Rio de Janeiro: IBGE; 2013 [cited 16 Dec 29]. Available from: ftp://ftp. ibge.gov.br/Pib_Municipios/2010_2013/xIs/PIBMunicipal_2010_2013.xls 
6. Instituto Brasileiro de Geografia e Estatística. Censo Demográfico 2010. Rio de Janeiro: IBGE; c2016 [cited 2016 Dec 29]. Available from: http://www.ibge.gov.br/home/estatistica/populacao/censo2010

7. Programa das Nações Unidas para o Desenvolvimento. Índice de Desenvolvimento Humano de Munícipios - 2010. Brasília (DF): PNUD-Brasil; 2010 [cited 2016 Dec 29]. Available from: http:// www.br.undp.org/content/brazil/pt/home/idh0/rankings/idhm-municipios-2010.html

8. Departamento de Informática do SUS. Rede Assistencial: Cadastro Nacional de Estabelecimentos de Saúde: Recursos Humanos. Brasília (DF); DATASUS; c2016 [cited 2016 Dec 29]. Available from: http://datasus.saude.gov.br/informacoes-de-saude/tabnet/rede-assistencial

9. Day AC, Donachie PH, Sparrow JM, Johnston RL; Royal College of Ophthalmologists' National Ophthalmology Database. The Royal College of Ophthalmologists' National Ophthalmology Database study of cataract surgery: report 1, visual outcomes and complications. Eye (Lond). 2015;29(4):552-60. https://doi.org/10.1038/eye.2015.3

10. Tolomei LA, Hashimoto M, Mazeto CFS, Shimauti AT, Silva MRBM, Padovani CR, et al. Air-Puff Tonometry in population research: a comparison with Goldmann tonometer in individuals with suspected ocular hypertension. Rev Bras Oftalmol. 2016;75(3):209-13. https://doi.org/10.5935/0034-7280.20160043

11. Tabin G, Chen M, Espandar L. Cataract surgery for the developing world. Curr Opin Ophthalmol. 2008;19(1):55-9. https://doi.org/ 10.1097/ICU.0b013e3282f154bd

12. Vargas MA, Rodrigues MLV. Perfil da demanda em um serviço de Oftalmologia de atenção primária. Rev Bras Oftalmol. 2010;69(2):77-83. https://doi.org/10.1590/S0034-72802010000200002

13. Dobbelsteyn D, McKee K, Bearnes RD, Jayanetti SN, Persaud DD, Cruess AF. What percentage of patients presenting for routine eye examinations require referral for secondary care? A study of referrals from optometrists to ophthalmologists. Clin Exp Optom. 2015;98(3):214-7. https://doi.org/10.1111/cxo.12255

14. Salomão SR, Cinoto RW, Berezovsky A, Araújo-Filho A, Mitsuhiro MR, Mendieta L, et al. Prevalence and causes of vision impairment and blindness in older adults in Brazil: the Sao Paulo Eye Study. Ophthalmic Epidemiol. 2008;15(3):167-75. https://doi. org/10.1080/09286580701843812

15. Silva JC, Mújica OJ, Vega E, Barcelo A, Lansingh VC, McLeod J, et al. A comparative assessment of avoidable blindness and visual impairment in seven Latin American countries: prevalence, coverage, and inequality. Rev Panam Salud Publica. 2015;37(1):13-20.

16. Foster A. Cataract and "Vision 2020-the right to sight" initiative. Br J Ophthalmol. 2001;85(6):635-7. https://doi.org/10.1136/bjo.85.6.635

17. World Health Organization. Programme for the Prevention of Blindness and Deafness. Global Initiative for the Elimination of Avoidable Blindness. Geneva: WHO; 2000 [cited 2016 Dec 29] Available from: http://apps.who.int/iris/bitstream/10665/63748/1/WHO_PBL_97.61_Rev.2.pdf

18. Prokofyeva E, Wegener A, Zrenner E. Cataract prevalence and prevention in Europe: a literature review. Acta Ophthalmol. 2013;91(5):395-405. https://doi.org/10.1111/j.1755-3768.2012.02444.x

19. Duan XR, Liang YB, Wang NL, Wong TY, Sun LP, Yang XH, et al. Prevalence and associations of cataract in a rural Chinese adult population: the Handan Eye Study. Graefes Arch Clin Exp Ophthalmol. 2013;251(1):203-12. https://doi.org/10.1007/s00417-012-2012-x

20. Mines MJ, Bower KS, Lappan CM, Mazzoli RA, Poropatich RK. The United States Army Ocular Teleconsultation program 2004 through 2009. Am J Ophthalmol. 2011;152(1):126-32 e2. https://doi.org/10.1016/j.ajo.2011.01.028

21. Kara-Júnior N, Dellapi Jr R, Espíndola RF. Dificuldades de acesso ao tratamento de pacientes com indicação de cirurgia de catarata nos Sistemas de Saúde Público e Privado. Arq Bras Oftalmol. 2011;74(5):323-5. https://doi.org/10.1590/S0004-27492011000500002

22. Lewallen $\mathrm{S}$, Courtright P. Recognising and reducing barriers to cataract surgery. Community Eye Health. 2000;13(34):20-1.

23. Breusegem C, Fieuws S, Stalmans I, Zeyen T. Agreement and accuracy of non-expert ophthalmologists in assessing glaucomatous changes in serial stereo optic disc photographs. Ophthalmology. 2011;118(4):742-6. https://doi.org/10.1016/j.ophtha.2010.08.019

24. Jampel HD, Friedman D, Quigley H, Vitale S, Miller R, Knezevich F, et al. Agreement among glaucoma specialists in assessing progressive disc changes from photographs in open-angle glaucoma patients. Am J Ophthalmol. 2009;147(1):39-44 e1. https://doi.org/10.1016/j.ajo.2008.07.023 
25. Azuara-Blanco A, Burr J, Thomas R, Maclennan G, McPherson S. The accuracy of accredited glaucoma optometrists in the diagnosis and treatment recommendation for glaucoma. $\mathrm{Br} J$ Ophthalmol. 2007;91(12):1639-43. https://doi.org/10.1136/bjo.2007.119628

26. Nicolela MT, Drance SM, Broadway DC, Chauhan BC, McCormick TA, LeBlanc RP. Agreement among clinicians in the recognition of patterns of optic disk damage in glaucoma. Am J Ophthalmol. 2001;132(6):836-44. https://doi.org/10.1016/S0002-9394(01)01254-5

27. Gupta SC, Sinha SK, Dagar AB. Evaluation of the effectiveness of diagnostic \& management decision by teleophthalmology using indigenous equipment in comparison with in-clinic assessment of patients. Indian J Med Res. 2013;138(4):531-5.

28. Thanigasalam T, Sahoo S, Ali MM. Posterior capsule rupture with/without vitreous loss during phacoemulsification in a hospital in Malaysia. Asia Pac J Ophthalmol (Phila). 2015;4(3):166-70. https://doi.org/10.1097/apo.0000000000000056

29. Ti SE, Yang YN, Lang SS, Chee SP. A 5-year audit of cataract surgery outcomes after posterior capsule rupture and risk factors affecting visual acuity. Am J Ophthalmol. 2014;157(1):180-5.e1. https://doi.org/10.1016/j.ajo.2013.08.022

30. Amin A, Ayub T, Samuel S. Rate of posterior capsular rent as a complication of resident performed cataract extraction procedures. J Ayub Med Coll Abbottabad. 2015;27(2):304-6.

Authors' Contribution: Design and planning of the study: GAF, RLFSM, SAS. Collection, analysis, and interpretation of the data: GAF, MAR. Preparation or review of the study: GAF, RLFSM, SAS. Approval of the final version: GAF, SAS. Public responsibility for the content of the article: GAF

Conflict of Interest: The authors declare no conflict of interest. 